\title{
EXERGAMES NA EDUCAÇÃO FÍSICA: UMA REVISÃO SISTEMÁTICA
}

\author{
EXERGAMES IN PHYSICAL EDUCATION: A SYSTEMATIC REVIEW
}

EXERGAMES EN EDUCACIÓN FÍSICA: UNA REVISIÓN SISTEMÁTICA

João Gabriel Eugênio Araújo*, Cleyton Batista**, Diego Luz Moura**

\begin{abstract}
Palavras chave: Desenvolvimento de tecnologias. Jogos de vídeo. Atividades científicas e tecnológicas. Aprendizagem.

Resumo: 0 objetivo deste estudo foi analisar a produção acadêmica sobre a utilização dos exergames nas aulas de Educação Física Escolar. Utilizou-se uma revisão sistemática qualitativa para a obtenção dos artigos selecionados. Foram encontrados treze trabalhos indexados nas bases de dados Medline, Lilacs, Scielo e DOAJ. Constatouse que os exergames são uma alternativa viável para o campo educacional e podem auxiliar no processo de ensino-aprendizagem. Além disso, quando aliados a atividades em ambiente real podem motivar os alunos e aumentar o nível de atividade física. Entretanto, observamos limitações metodológicas que comprometem a validade dos achados apresentados. Reforçamos a necessidade de mais pesquisas que busquem avaliar criticamente as potencialidades pedagógicas de tais equipamentos na Educação Física Escolar.
\end{abstract}

\section{Keywords:}

Technology development. Videogames. Scientific and technical activities. Learning. Desarrollo tecnológico. Videojuegos. Actividades científicas y tecnológicas. Aprendizaje.
Abstract: The aim of this study was to analyze academic literature on the use of exergames in school Physical Education classes. A qualitative systematic review was conducted to obtain the selected articles. Thirteen papers were found indexed in the databases Medline, Lilacs, Scielo and DOAJ. Exergames were found to be are a viable alternative for the educational field. They can assist in teaching and learning processes. Moreover, when combined with activities in actual environments, they can motivate students and increase their level of physical activity. However, we found methodological limitations that compromise the validity of the findings. We emphasize the need for more research that seeks to critically assess the pedagogical potential of such equipment in Physical Education.

Resumen: El objetivo de este estudio fue analizar la literatura académica sobre la utilización de los exergames en las clases de Educación Física escolar. Se ha utilizado de una revisión sistemática cualitativa para la obtención de los artículos seleccionados. Han sido encontrados trece trabajos indexados en las bases de datos Medline, Lilacs, Scielo y DOAJ. Se concluyó que los exergames son una alternativa viable para el campo educacional y pueden auxiliar en el proceso de enseñanza y aprendizaje. Además, cuando están aliados a actividades en ambiente real, pueden motivar a los alumnos y aumentar el nivel de actividad física. Sin embargo, observamos limitaciones metodológicas que comprometen la validez de los resultados presentados. Reforzamos la necesidad de más investigaciones que busquen evaluar críticamente las potencialidades pedagógicas de esos materiales en la Educación Física escolar.
*Instituto Federal de Pernambuco. Afogados da Ingazeira, PE, Brasil. E-mail: joao.araujo@afogados.ffpe.edu.br

${ }^{*}$ Universidade Federal do Vale do São Francisco. Petrolina, PE, Brasil. E-mail: cleytonbatista1@ hotmail.com

Recebido em: 11-06-2016 Aprovado em: 14-02-2017

(c) (1) (8) Licence 


\section{INTRODUÇÃO}

A presença das novas tecnologias tem ajudado as pessoas em seu cotidiano. Nas últimas décadas surgiu uma série de inovações tecnológicas que beneficiam a vida dos indivíduos. Esse impacto é significativo e interfere nas relações dos indivíduos, dando origem a novas práticas sociais.

No campo educacional, as novas tecnologias estão se apresentando de inúmeras formas, como, por exemplo: indicador de luz para o quadro, lousas interativas, jogos digitais (JDs) ou programas de ensino em plataformas online. No Brasil, é crescente a oferta de cursos na modalidade a distância (EAD1). De acordo com o Censo da Educação Superior de 2014, divulgado em 2015, o número de alunos que utilizam a modalidade a distância foi de 1,34 milhão, o que representa 17,1\% das matrículas no ensino superior em 2014 (BRASIL, 2015).

Caparróz e Lopes (2008) apontam que a presença das Tecnologias da Informação e Comunicação (TICs) na educação proporciona novas possibilidades de intervenção no processo de ensino-aprendizagem. Nessa perspectiva, Moura e Sousa (2014) reforçam que é necessário maior foco na formação dos professores para melhor utilizar as TICs.

Todavia, algumas tecnologias são desvalorizadas nesse processo, por exemplo, os JDs tradicionais, que não permitem maior interação ou movimento corporal e foram associados à introversão social, promoção de comportamento agressivo (ALVES; CARVALHO, 2011), síndromes musculoesqueléticas, problemas do sono e problemas auditivos (JANNINE, 2011), além de terem sido associados ao sedentarismo, à obesidade e aos maus hábitos alimentares (ENES; SLATER, 2010). No entanto, estudos como o de Finco e Fraga (2012; 2013), Vaghetti e Botelho (2010), Marchetti et al. (2011), Perez, Neiva e Monteiro (2014) atribuem a uma nova plataforma de videogames possibilidades de interação motora com os JDs, a esses jogos dá-se o nome de "exergames".

Segundo Finco e Fraga (2012), os exergames são envolventes, apresentam desafios, possibilitam realizar atividades físicas e permitem interação com outras pessoas. Neles, os jogadores realizam a ação e o console "lê" os movimentos e aplica-os ao jogo. Os exergames são objetos de pesquisa em diferentes temáticas, como: a reabilitação (SPOSITO et al., 2013; MUSSATO; BRANDALIZE; BRANDALIZE, 2012), saúde e desenvolvimento da forma física (RAUBER et al., 2013;), aprendizagem escolar (ARAÚJO et al., 2011; BARACHO; GRIPP; LIMA, 2012; SCHWARTZ et al., 2013; VAGHETTI; BOTELHO, 2010) motivação e aderência a programas de atividades físicas (FINCO; FRAGA, 2012; 2013).

É preciso superar a resistência ao uso dos JDs na educação, que está em grande parte relacionada à visão de que são atividades desenvolvidas por adolescentes que perdem horas de estudo e são estimulados a atos de violência e perversidade (BANCO NACIONAL DE DESENVOLVIMENTO ECONÔMICO E SOCIAL, 2014). Segundo Cruz Junior (2014, p. 942), "[...] uma das hipóteses proveniente desse cenário é a de que os games estariam gradualmente 'substituindo' os jogos tradicionais, relegando o corpo e o movimento a lugares cada vez mais periféricos". Entretanto, a inclusão dessas tecnologias anuncia-se como uma nova realidade. Desde sua publicação, os Parâmetros Curriculares Nacionais (BRASIL, 1997) apontam que a escola deve se apropriar criticamente das novas tecnologias, possibilitando a aquisição de novas competências para lidar com as inovações de uma sociedade digital. 
Para Perez, Neiva e Monteiro (2014), JDs são ferramentas importantes no processo de ensino-aprendizagem, pois trabalham habilidades cognitivas, atenção visual, memória e resolução de problemas, além de promoverem um lugar para vivência do lúdico, tornandose um espaço prazeroso e motivador para o aprendizado. Nesse sentido os exergames são alternativas viáveis nesse processo, pois além de abordarem as ferramentas citadas, possibilitam interação entre 0 ambiente virtual com as habilidades motoras, visuais e sensoriais dos praticantes.

Para Gee (2009), bons JDs podem favorecer o aparecimento de princípios como: identidade, interação, customização, desafio, sentidos contextualizados, pensamento sistemático, exploração, revisão dos objetivos, conhecimento distribuído e outros.

No ambiente escolar a Educação Física (EF) deve ser um espaço onde se possam ensinar conceitos, atitudes e experiências de movimento relevantes para a vida dos jovens (FERREIRA; GRAEBNER; MATIAS, 2014). Entretanto, alguns conteúdos são menos privilegiados, como as danças e as lutas. Tais modalidades fazem parte desse conjunto de práticas corporais culturalmente adquiridas pela humanidade que são minimamente abordadas ou excluídas das aulas (DINIZ; DARIDO, 2012).

Os exergames podem tornar-se uma ferramenta pedagógica viável no processo de ensino-aprendizagem, principalmente em se tratando de conteúdos negligenciados. É importante conhecer e compreender como esses jogos podem auxiliar alunos e professores durante as aulas de EF. Assim, o objetivo deste estudo foi analisar a produção acadêmica sobre a utilização dos exergames nas aulas de EF Escolar.

\section{METODOLOGIA}

O método utilizado foi a revisão sistemática qualitativa, que possibilita considerar as similaridades e diferenças significativas entre as pesquisas já realizadas, ampliando, assim, as possibilidades interpretativas das pesquisas, construindo releituras ampliadas (GOMES; CAMINHA, 2014).

Dois pesquisadores, de forma independente, realizaram buscas nas bases de dados. Avaliaram e selecionaram os estudos, considerando os estudos relevantes, a correspondência entre o registrado pelo pesquisador e o conteúdo, a credibilidade dos métodos empregados e a aplicabilidade dos achados (DE-LA-TORRE-UGARTE-GUANILO; TAKAHASHI; BERTOLOZZI, 2011).

A busca dos artigos selecionados para essa revisão foi realizada nas seguintes bases de dados: Medline, ${ }^{2}$ Lilacs, ${ }^{3}$ SciElo ${ }^{4}$ e DOAJ". Os descritores selecionados foram: "jogos", "exergames", "jogos eletrônicos", "videogames" e "novas tecnologias". A consulta foi realizada em artigos em inglês e em português. Os critérios de inclusão e exclusão foram definidos consensualmente pelos dois pesquisadores. Apresentamos na Tabela 1 o número inicial de artigos encontrados nas bases de dados a partir de cada descritor.

\footnotetext{
2 Disponível em:<http://bases.bireme.br/cgi-bin/wxislind.exe/iah/online/?!sisScript=iah/iah.xis\&base=MEDLINE\&lang=p\&form=F> 
Tabela 1 - Número inicial de artigos encontrados por descritor e indexador

\begin{tabular}{cccccc}
\hline & \multicolumn{5}{c}{ Descritores } \\
\cline { 2 - 6 } Indexadores & Jogos & Exergames & $\begin{array}{c}\text { Jogos } \\
\text { eletrônicos }\end{array}$ & Videogames & $\begin{array}{c}\text { Novas } \\
\text { tecnologias }\end{array}$ \\
\cline { 2 - 6 } Medline & 6668 & 114 & 10 & 168 & 35 \\
Lilacs & 658 & 9 & 26 & 40 & 302 \\
Scielo & 433 & 3 & 22 & 63 & 458 \\
DOAJ & 494 & 23 & 32 & 200 & 551 \\
\hline
\end{tabular}

Fonte: próprios autores.

Como critérios de inclusão estabelecemos: a) tematizar a utilização de JDs nas aulas de EF; b) debater sobre os exergames na EF; c) o arco temporal entre 2010 e 2015 (outubro); d) pesquisas no formato artigo originais, ensaios, resenhas e resumos. Já o critério de exclusão: a) utilizar os exergames na reabilitação de escolares.

Através de uma leitura inicial do título e do resumo foram selecionados 59 artigos, entretanto, 15 artigos idênticos foram encontrados em mais de uma base de dados, assim 44 artigos restaram, como ilustra a Tabela 2 abaixo.

Tabela 2 - Número de artigos após a filtragem por títulos e resumos

\begin{tabular}{cccccc}
\hline & \multicolumn{5}{c}{ Descritores } \\
\cline { 2 - 6 } Indexadores & Jogos & Exergames & $\begin{array}{c}\text { Jogos } \\
\text { eletrônicos }\end{array}$ & Videogames & $\begin{array}{c}\text { Novas } \\
\text { tecnologias }\end{array}$ \\
\hline Medline & 8 & 6 & 2 & 5 & 0 \\
Lilacs & 5 & 1 & 3 & 1 & 1 \\
Scielo & 3 & 2 & 1 & 3 & 0 \\
DOAJ & 0 & 2 & 0 & 1 & 0
\end{tabular}

Entretanto, ao aplicar os critérios de inclusão, 26 foram descartados. Ao aplicar 0 critério de exclusão aos 18 artigos restantes, foram retirados mais cinco estudos. Assim, 13 artigos foi o número final a ser analisado na presente pesquisa.

Tais artigos foram analisados a partir da técnica de análise de conteúdo (BARDIN, 2011) com ênfase a dois aspectos: analisar a estratégia metodológica utilizada e levantar os principais achados de cada artigo analisado.

\section{RESULTADOS E DISCUSSÃO}

A presente seção tem por objetivo apresentar os dados encontrados com a análise dos 13 artigos. Organizamos os principais temas abordados em cinco categorias: Contribuições no processo de ensino-aprendizagem; Aumento no nível de atividades físicas nas aulas de EF; Motivação nas aulas de EF; Importância do design dos exergames; Minimizar as limitações dos professores sobre os exergames nas aulas. As categorias foram construídas após a análise dos textos como uma estratégia didática para facilitar a compreensão do debate. Os artigos podem estar presentes em mais de uma categoria. 


\subsection{Contribuições no processo de ensino-aprendizagem}

Nessa categoria, encontram-se seis artigos que buscaram relacionar as contribuições dos exergames no processo de ensino-aprendizagem. Dentre o total de artigos, três realizaram revisão de literatura e três pesquisas de campo.

O argumento central nestes artigos está relacionado com o potencial que o componente lúdico presente nos JDs pode constituir-se como estímulo para o desenvolvimento integral dos alunos (VAGHETTI; BOTELHO, 2010). A partir de suas características básicas - a imersão, a interação e o envolvimento - é possível pensar a utilização dos exergames como meio de ampliação das formas de ensino-aprendizagem dos diversos conteúdos da EF (BARACHO; GRIPP; LIMA, 2012).

Gao et al. (2013) analisaram durante os anos de 2009 e 2010 o impacto do jogo de dança "Dance Dance Revolutionß" (DDR) na aptidão física e no desempenho acadêmico de escolares. As intervenções foram feitas durante os intervalos das aulas com duração de 30 minutos, três vezes por semana. Não foi informada a quantidade de intervenções realizadas. Metodologia semelhante foi utilizada por Baracho, Gripp e Lima (2012), aos quais 117 voluntários responderam questionários sobre a presença das TICs e o fenômeno da virtualidade no cotidiano. Em seguida selecionaram oito destes participantes, que nunca jogaram exergames, para praticar o jogo beisebol no Wii Sports em horário extracurricular e, em seguida, realizaram o beisebol na prática.

Os resultados de ambos os estudos afirmam que os exergames contribuem para 0 processo de ensino-aprendizagem. Entretanto, no caso de Gao et al. (2013), faltaram maiores esclarecimentos acerca da metodologia, o que produziu uma série de vieses. Os autores sustentam que a melhora no desempenho acadêmico é justificada pelos exergames influenciarem na atividade cerebral, assim contribuindo para melhora do desempenho acadêmico. No entanto, não houve métodos de investigação apresentados que comprovassem tais influências. Outro problema é que não houve testes anteriores que identificassem em qual nível acadêmico (notas) estavam os alunos voluntários, além disso, a melhora das notas em matemática e leitura pode ser atribuída pela mudança no conteúdo da disciplina (um conteúdo com menor complexidade que os anteriores), ou aumentos das horas de estudo em casa. A falta de informações, como a quantidade de intervenções feitas durante os anos da pesquisa, é falha que conduz a vieses. Esses são fatores que deveriam ter sido controlados e relatados na pesquisa. Devido a isso não há como afirmar que os exergames contribuem para a melhora do desempenho acadêmico em matemática e leitura.

Já Baracho, Gripp e Lima (2012, p. 122) contribuem com avanços sobre a utilização dos exergames no cotidiano dos jovens. Para eles essa cultura digital, na qual está presente o exergame, "é uma via inevitável, um caminho a ser percorrido pela atual e futura geração". Apontam que é necessário interagir e utilizar essa ferramenta de forma reflexiva e estratégica, contribuindo para dinamizar o processo de ensino-aprendizagem, pois incorpora a possibilidade de novas experiências corporais de movimento.

Araújo et al. (2011) analisaram os processos de virtualização esportiva, ligados aos JDs, sua interferência na cultura corporal e as possíveis implicações para a EF. Foram realizadas entrevistas com 30 alunos de uma escola pública. Apesar de não ter realizado uma intervenção 
com os exergames, a pesquisa demonstrou a presença dessas ferramentas no cotidiano dos voluntários. No entanto, as entrevistas confirmaram que 0 ambiente virtual influencia 0 comportamento dos alunos. Segundo os autores a utilização dos exergames é um relevante mecanismo de socialização, diversão e aprendizado.

Podemos perceber a existência de pesquisas apontando as contribuições dos exergames no processo de ensino-aprendizagem. Porém, ainda faltam pesquisas que abordem essa temática com maior profundidade. A maior parte das pesquisas que abordam esse processo não a trata como objeto principal, visto que, dos seis artigos, três são revisões sobre aspectos diversos dos exergames, inclusive a utilização dessa ferramenta no processo de ensino-aprendizagem. Dentre os outros três artigos dessa categoria, um apresenta uma série de vieses, o outro não aborda especificamente o processo de ensino-aprendizagem, e sim a presença dos exergames e suas contribuições na cultura digital, chamado por eles de cibercultura. 0 único artigo que tem foco sobre o processo de ensino-aprendizagem é o de Baracho, Gripp e Lima (2012).

Portanto, mesmo com grande incidência de artigos que focalizam o processo de ensinoaprendizagem, há poucas contribuições pertinentes e que possam colaborar com o avanço da utilização dos exergames como ferramenta de apoio ao processo de ensino-aprendizagem da EF.

\subsection{Aumento no nível de atividade física nas aulas de EF}

Dos 11 artigos presentes nessa categoria, oito são pesquisas de campo e três revisões. A preocupação com o baixo nível de atividade física entre crianças e adolescentes é o foco da utilização dos exergames nas aulas de EF.

As pesquisas relacionadas nessa categoria afirmam o aumento no nível de atividades físicas com o uso dos exergames em comparação aos videogames que não utilizam 0 movimento. Logo, apontam que esta poderá tornar-se uma ferramenta para o enfrentamento do sedentarismo e da inatividade física.

Para Lwin e Malik (2014), a incorporação dos exergames nas aulas de EF Escolar pode provocar efeitos positivos ao influenciar a prática de atividades físicas. Para isso, foi realizada pesquisa com 398 alunos divididos em três escolas de Singapura. Cada classe foi designada para uma condição experimental diferente: classe com jogos digitais e classe com jogos reais. A análise foi feita durante seis semanas de intervenção com intervenções de 45 minutos. No entanto, não foi relatado o número de sessões totais. Apontou-se que o tempo gasto assistindo televisão ou jogando videogames sem movimento é um dos responsáveis pela diminuição do nível de atividade física. Em contrapartida, a presença das novas tecnologias como no caso dos exergames pode proporcionar um novo olhar sobre essa prática de entretenimento e sua relação com as aulas de EF.

Sobre essa relação entre JDs, exergames e atividades físicas tradicionais os autores apresentam dados interessantes. Sun (2012) comparou turmas que utilizam os exergames com outras que utilizaram atividades físicas tradicionais. Foram selecionados 74 jovens, que realizavam duas vezes por semana 30 minutos de atividades com exergames. Ao total foram 32 intervenções em duas unidades. Constatou-se que a unidade com atividades tradicionais 
foi mais efetiva na melhoria da condição cardiorrespiratória. Já na unidade com exergames os resultados não foram significativos para uma considerável melhoria. Na pesquisa de Lwin e Malik (2014), os autores apontam que o gasto calórico foi maior que o apresentado por JDs sedentários, porém, inferiores às atividades físicas tradicionais.

Outros estudos chegaram a essa mesma conclusão ao comparar o jogo em ambiente virtual com real. Baracho; Gripp; Lima (2012) constataram, através das entrevistas, que as atividades com exergames não proporcionaram cansaço físico entre os participantes. Isso pode ser atribuído à escolha dos participantes, pois quanto menos experiência com o jogo, menor é o gasto de energia com sua prática (SELL et al., 2008 apud MARCHETTI et al., 2011). Outro fator que pode ter contribuído foi a escolha do esporte. $O$ beisebol, por não ser comum na cultura de movimento brasileira, não desperta tanto interesse. Devido a isso, sua abordagem pode ter influenciado negativamente a prática do esporte no ambiente virtual.

O aumento no nível de atividades físicas, através da utilização dos exergames, foi relatado em outras pesquisas. Os estudos de Shayne et al. (2012) e Fogel et al. (2010) fizeram intervenção semelhante. As pesquisas foram feitas em uma turma com 25 alunos, dos quais apenas quatro participaram da pesquisa. A turma realizou atividades com exergames duas vezes por semana durante um ano letivo (não foi relatada a quantidade total de intervenções). Em ambas as pesquisas foram comparados os efeitos da utilização de exergames com a prática de atividades tradicionais em uma classe de EF. A diferença entre as pesquisas é que Fogel et al. (2010) utilizaram uma amostra com crianças inexperientes com exergames, inativas, com sobrepeso e baixo condicionamento físico. Enquanto Shayne et al. (2012) utilizaram amostra de crianças com experiência com exergames, ativas, com peso normal e com bom condicionamento físico. Ambas as pesquisas citadas anteriormente apontam que houve um aumento no nível de atividades físicas em comparação aos JDs sedentários, mas quanto à melhora no condicionamento cardiorrespiratório não houve resultados conclusivos. Principalmente, devido à forma como os participantes foram avaliados. Não houve a utilização de instrumentos para a coleta, apenas uma observação dos voluntários pelo professor (uma espécie de diário de campo) foi utilizada para comprovar o nível de atividade física, devido a isso, vários vieses surgiram, pois essa é uma análise subjetiva de esforço sugerido pelo observador e não pelos praticantes da atividade.

A preocupação em melhorar o currículo da EF Escolar através da incorporação dos exergames está presente em Quinn (2013). Ele utilizou seis semanas para incorporar os exergames em uma sala de aula tradicional. Eram cinco sessões por semana, com duração de 42 minutos. A amostra foi composta por 86 alunos e os professores tiveram treinamento para utilizar os exergames. Diferentemente das pesquisas de Shayne et al. (2012) e de Fogel et al. (2010), houve mecanismos de avaliação geral das atividades físicas (testes pré e pósintervenção). Os alunos participavam de jogos reais e jogos nos exergames. Os resultados indicaram que os alunos foram significativamente mais ativos nas aulas depois da intervenção com exergames. A utilização dessa ferramenta contribuiu, também, para influenciar a prática de atividades físicas nos momentos de lazer. No entanto, o período de seis semanas é curto para apresentar qualquer alteração significativa no comportamento, assim são necessários estudos que investiguem um maior tempo de intervenção com exergames.

Finco, Reategui e Zaro (2015) realizaram uma intervenção durante três meses com 24 alunos desmotivados com as aulas regulares de EF. A amostra participou de um laboratório 
de exergames. Esse local foi estruturado como espaço complementar para as aulas, em que uma das aulas semanais era realizada no laboratório de exergames e a outra na EF regular. Cada sessão teve duração de uma hora e no máximo quatro alunos poderiam, na mesma hora, utilizar o laboratório. Para a coleta dos dados foi utilizado um diário de campo para identificar as contribuições dos exergames na prática de atividades físicas e no desenvolvimento de habilidades sociais. Esse estudo se mostra válido ao proporcionar a alunos desmotivados uma alternativa de envolvimento com a atividade física. No mesmo sentido, Sun (2012) sugere que os professores utilizem os exergames de maneira intercalada com as atividades reais, ou seja, para ele JDs devem ser utilizados para introduzir ou iniciar a vivência de alguma modalidade ou exercício, que posteriormente seria abordado no ambiente natural da modalidade. Esse tipo de abordagem pode proporcionar diferentes experiências motoras aos alunos, possibilitando maior aderência ao conteúdo.

É uma busca constante das pesquisas a comprovação do aumento do nível de atividades físicas através da utilização dos exergames nas aulas de EF. Entretanto, constatamos que os resultados apresentados não possuem um rigor metodológico. Os testes e equipamentos utilizados não dão suporte aos achados sugeridos pelas pesquisas. Assim, para constatar de maneira eficaz as contribuições dos exergames para a melhoria dos níveis de atividade física, é necessária a realização de mais pesquisas preocupadas com o seu delineamento metodológico. De acordo com as pesquisas analisadas, a prática real dos jogos proporciona um gasto energético mais significativo, além de melhorar a condição física dos praticantes. Enquanto isso, os exergames necessitam de mais pesquisas relacionadas a essa temática para comprovar sua eficácia na melhoria do condicionamento físico.

\subsection{Motivação nas aulas de EF}

Nesta categoria, encontram-se oito artigos que relacionaram as contribuições dos exergames na motivação durante as aulas de EF. Dentre o total de artigos, sete realizaram pesquisa de campo e um deles, uma revisão de literatura.

Sun (2012) explora o impacto dos exergames na motivação dos alunos em comparação com as atividades reais. Foi aplicada escala Likert para avaliar o interesse situacional. Constatou-se que o interesse situacional foi maior na unidade com exergames que com jogos reais. Quinn (2013) teve proposta semelhante, introduzir os exergames no currículo. Constatouse um aumento no nível de atividade física e participação nas aulas e no lazer, motivando a prática de atividade física fora da escola. Entretanto, os instrumentos utilizados para verificar 0 aumento na motivação não estão descritos na metodologia.

Lwin e Malik (2014), ao realizar as atividades com exergames e no ambiente real, introduziram mensagens educativas sobre saúde, tentando influenciar a atitude de crianças em relação à prática de atividade física. Foram utilizadas escalas de atitude e medidas de "autoeficácia". A utilização combinada dos exergames às mensagens educativas sobre saúde surtiu efeito positivo ao influenciar as crianças na realização de atividades físicas. Os autores apontam que seis semanas de intervenção podem ser insuficientes para alterar significativamente o comportamento das crianças.

Verificou-se que os exergames podem ser uma alternativa viável para motivar os alunos nas aulas de EF Escolar, pois proporcionam momentos de interação, socialização e diversão. 
Os exergames podem ser um recurso que potencializa o espaço da sala de aula tradicional, podendo motivar os alunos, pois são dotados de alto poder de ilustração e constituem-se como uma ferramenta educacional que oportuniza diferentes experiências (BARACHO; GRIPP; LIMA, 2012).

A falta de motivação para participar das aulas de EF foi o principal fator na escolha da amostra no estudo de Finco, Reategui e Zaro (2015). O laboratório de exergames foi destinado a alunos desmotivados com as aulas regulares de EF. $O$ objetivo do laboratório foi incentivar a prática de exercícios e permitir trabalhar outras habilidades. Algumas afirmações a respeito do interesse situacional, interação e engajamento com as atividades poderiam ser entendidas melhor se tivesse sido utilizado algum tipo de questionário que fortalecesse as afirmações postas no diário de campo. As afirmações sobre a melhoria na interação social e na colaboração poderiam ser confirmadas se uma entrevista por grupo focal fosse feita com os participantes. No entanto, apenas o diário de campo e a entrevista com o professor foram utilizados.

A entrevista semiestruturada foi utilizada por Araújo et al. (2011) para analisar os processos de virtualização esportiva ligada aos JDs. Percebeu-se que os exergames são um relevante mecanismo de socialização, diversão e aprendizado. Foi adotada a metodologia qualitativa descritiva de campo, em que foram realizadas entrevistas com 30 atores entre $11 \mathrm{e}$ 15 anos de idade do ensino fundamental de duas escolas. $O$ artigo traz um olhar diferenciado sobre a utilização dos exergames na EF. O uso das entrevistas foi relevante nesse sentido, pois permitiu verificar o que pensam e fazem os alunos a partir dos JDs.

A participação durante as aulas de EF e a motivação empregada nas aulas deve ser incentivada e encorajada. A utilização de novas ferramentas tecnológicas, como os exergames, pode tornar-se um aliado no combate à inatividade física. No entanto, não se deve encarar o JDs como substituto do ambiente real de aprendizagem, mas sim como movimento de inovação que, nesse caso, expande as possibilidades do movimento humano (BARACHO; GRIPP; LIMA, 2012). Esse pode ser um dos caminhos para a EF Escolar recuperar o interesse dos alunos pela disciplina e pelo movimento corporal.

\subsection{Importância do design dos exergames para obter melhor envolvimento dos praticantes nas aulas}

Nessa categoria cinco artigos são relacionados. Três pesquisas de campo e duas revisões. 0 design dos JDs, a velocidade de interação com o jogador, as interfaces mais sofisticadas e outros fatores relacionados a descobertas tecnológicas têm contribuído para conquistar mais adeptos.

A pesquisa de Sgrò et al. (2013) é o único artigo que se propôs a discutir mais especificamente o design dos exergames. $\mathrm{Na}$ ocasião da publicação apenas a revisão de literatura foi concluída. Sua principal contribuição está vinculada à busca por avanços tecnológicos mais significativos em responder a movimentos da tela dos exergames, a comparação entre a representação mental, o padrão motor do jogador e a representação baseada na tela.

Através dos artigos relacionados constatou-se que nem todos os exergames são viáveis para as aulas de EF, pois apresentaram problemas durante algumas coletas. Shayne et 
al. (2012) relataram que devido a falhas no equipamento e ao alto custo o modelo utilizado nas intervenções com exergames deve ser revisto. Foram nove estações com exergames, cada sessão teve duração de 30 minutos; dificilmente uma escola terá tantos aparelhos disponíveis.

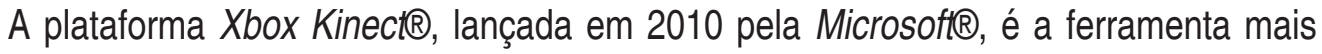
aconselhada para as aulas de EF, essa opinião é compartilhada por Di Tore et al. (2011) e por Sgrò et al. (2013). Isso se deve ao Kinec® representar a solução mais útil para compartilhar experiências de exergames no ambiente educacional, além disso, tem alta difusão entre os jovens, flexibilidade tecnológica e custo acessível.

Além da plataforma de JDs mais indicada, a escolha do jogo também pode proporcionar maior envolvimento. O beisebol foi o esporte escolhido para a intervenção no estudo de Baracho, Gripp e Lima (2012). O fato de o beisebol não ser um esporte presente na cultura brasileira pode ter influenciado negativamente sua prática no real. Lwin e Malik (2014) relacionam 0 boxe como o esporte mais indicado para um maior gasto energético. Quinn (2013) iniciou sua pesquisa com a utilização do DDR, no entanto, esse jogo se mostrou confuso e difícil, fato que diminuiu o tempo ativo dos alunos. Em substituição ao DDR foi utilizado o Just Dance®, principalmente, devido a sua interface com o jogador ser mais simples, facilitando o aumento do tempo ativo, e a sua maior variedade de músicas.

\subsection{Minimizar as limitações dos professores sobre os exergames nas aulas}

Cinco artigos foram selecionados nessa categoria, são três pesquisas de campo e duas revisões. Esse não foi o principal tema abordado nos artigos. No entanto, a utilização dos exergames só poderá ser amplamente difundida se os profissionais envolvidos conseguirem visualizar as possibilidades educacionais dessa ferramenta pedagógica.

É necessário que o professor esteja preparado para interagir com as ferramentas tecnológicas mais próximas ao público jovem. Dentre elas, o exergame é a que mais se aproxima da cultura corporal, pois possibilita interação entre o corpo, os JDs e os conteúdos das aulas de EF. Todavia, constata-se a necessidade de capacitações que viabilizem sua utilização.

Sun (2012) proporcionou aos professores envolvidos uma formação para operar os exergames. A mesma preocupação teve Quinn (2013) com seus pesquisadores. Isso demonstra a importância de uma preparação adequada dos professores para atuar com essa ferramenta. Além disso, o uso inadequado e sem orientação apropriada dos exergames pode trazer riscos aos usuários (BARACHO; GRIPP; LIMA, 2012; MARCHETTI et al., 2011).

\section{CONSIDERAÇÕES FINAIS}

O presente artigo teve por objetivo analisar a produção acadêmica sobre a utilização dos exergames nas aulas de EF Escolar. Observamos que esse debate gira em torno de cinco categorias: Contribuições no processo de ensino-aprendizagem; Aumento no nível de atividade física nas aulas de EF; Motivação nas aulas de EF; Importância do design dos exergames; Minimizar as limitações dos professores sobre os exergames nas aulas.

Observamos que através da utilização dos exergames nas aulas de EF a produção aponta que estes podem: contribuir positivamente no processo de ensino-aprendizagem e 
no desenvolvimento integral dos alunos; promover um maior envolvimento dos alunos com a prática de atividade física, principalmente, se aliados a jogos em ambiente real; motivar e aumentar a aderência dos alunos durante as aulas; atrair mais participação, principalmente devido à tecnologia envolvida, fatores como liberdade de movimento e custo são importantes no momento da escolha dos JDs; além disso, o professor deve dominar e ser capaz de interagir pedagogicamente com essas ferramentas.

Todavia, também constatamos que a produção acadêmica apresenta diversas limitações de ordem metodológica, comprometendo a qualidade dos resultados apresentados. Embora os artigos anunciem uma série de benefícios a nível pedagógico, esses não se sustentam após uma análise crítica da metodologia e do procedimento de coleta. Contudo, não se pretende negar as pesquisas com olhares pedagógicos ou afirmar que não existem benefícios pedagógicos na utilização dos exergames. Nossa intenção foi alertar para necessidade de maior rigor metodológico nas pesquisas pedagógicas com exergames.

Constatamos que os JDs despontam como uma nova possibilidade para o campo educacional. Assim, reforçamos a necessidade de mais pesquisas que busquem avaliar criticamente as potencialidades pedagógicas de tais equipamentos na EF Escolar.

\section{REFERÊNCIAS}

ALVES, Luciana; CARVALHO, Alysson, Massote. Videogame: é do bem ou do mal? Como orientar pais. Psicologia em Estudo, v. 16, n. 2, p. 251-258, abr./ jun. 2011.

ARAÚJO, Bruno Medeiros Roldão de et al. Virtualização esportiva e os novos paradigmas para o movimento humano. Motriz, v. 17, n. 4, p. 600-609, out./dez. 2011.

BANCO NACIONAL DE DESENVOLVIMENTO ECONÔMICO E SOCIAL. BNDES. Relatório final: mapeamento da indústria brasileira e global de jogos digitais. Disponível em: <http://www.bndes.gov. br/SiteBNDES/bndes/bndes pt/Galerias/Arquivos/conhecimento/seminario/seminario mapeamento industria games042014 Relatorio Final.pdf>. Acesso em: 8 dez. 2014.

BARACHO, Ana Flávia de Oliveira; GRIPP, Fernando Joaquim; LIMA, Márcio Roberto de. Os exergames e a educação física escolar na cultura digital. Revista Brasileira de Ciências do Esporte, v. 34, n.1, p. 111-126, jan./mar. 2012.

BARDIN, Laurence. Análise de conteúdo. São Paulo: Edições 70, 2011.

BRASIL. Secretaria de Educação Fundamental. Parâmetros Curriculares Nacionais: introdução aos parâmetros curriculares nacionais. Brasília: MEC/SEF, 1997.

BRASIL. Instituto de Estudos e Pesquisas Educacionais Anísio Teixeira. Censo da Educação Superior 2014: notas estatísticas. 2015. Disponível em: <http://download.inep.gov.br/educacao superior/censo superior/documentos/2015/notas sobre o censo da educacao superior_2014.pdf>. Acesso em: 8 jun. 2016.

CAPARRÓZ, Adriana dos Santos Carvalho; LOPES, Maria Cristina Paniago. Desafios e perspectivas em ambientes virtuais de aprendizagem: inter-relações, formação tecnológica e prática docente.

Revista Educação, Formação e Tecnologia, v. 1, n. 2, p.50-58, 2008. 
CRUZ JUNIOR, Gilson. Burlando o círculo mágico: o esporte no bojo da gamificação. Movimento, v. 20, n. 3, p.941-963, jul./set. 2014.

DE-LA-TORRE-UGARTE-GUANILO, Mônica Cecília; TAKAHASHI, Renata Ferreira;

BERTOLOZZI, Maria Rita. Revisão sistemática: noções gerais. Revista da Escola de Enfermagem USP, v. 45, n. 5, p. 1260-1266, out. 2011.

DINIZ, Irlla Karla dos Santos; DARIDO, Suraya Cristina. Livro didático: uma ferramenta possível de trabalho com a dança na Educação Física Escolar. Motriz, v...v. 18, n. 1, p. 176-185, jan./mar. 2012.

DI TORE, Stefano et al. Didactics, movement and technology: new frontiers of the human - machine interaction. Journal of Sport and Exercise, v. 7, n. 1, p. 11-14, 2012.

ENES, Carla Cristina; SLATER, Betzabeth. Obesidade na adolescência e seus principais fatores determinantes. Revista Brasileira de Epidemiologia, v. 13, n. 1, p. 163-171, 2010.

FERREIRA, Mayara Luana Santos; GRAEBNER, Luciane; MATIAS, Thiago Sousa. Percepção de alunos sobre as aulas de Educação Física no Ensino Médio. Pensar a Prática, v. 17, n. 3, p. 734-750, jul./set. 2014.

FINCO, Mateus David; FRAGA, Alex Branco. Rompendo fronteiras na Educação Física através dos videogames com interação corporal. Motriz, v. 18, n. 3, p. 533-541, jul/set, 2012.

FINCO, Mateus David; FRAGA, Alex Branco. Corpo joystick. cinema, videogames e estilo de vida ativo. Licere, v. 16, n. 3, p. 1-19, set. 2013.

FINCO, Mateus David; REATEGUI, Eliseo Berni; ZARO, Milton Antônio. Laboratório de exergames: um espaço complementar para as aulas de educação física. Movimento, v. 21, n. 3, p. 687-699, jul./ set. 2015.

FOGEL, Victoria A. et al. The effects of exergaming on physical activity among inactive children in a physical education classroom. Journal Applied Behavior Analysis, v. 43, n. 4, p. 591-600, 2010.

GAO, Zan et al. Video game-based exercise, Latino children's physical health, and academic achievement. American Journal of Preventive Medicine, v. 44, n. 3, p. S240-S246, 2013.

GEE, James Paul. Bons videogames e boa aprendizagem. Perspectiva, v. 27, n.1, p.167-178, jan./ jun. 2009.

GOMES, Isabelle Sena; CAMINHA, Iraquitan Oliveira. Guia para estudos de revisão sistemática: uma opção metodológica para as ciências do movimento humano. Movimento, v. 20, n. 1, p. 395-411, jan./ mar. 2014.

JANNINE, Suely Nóbrega. Dor, lesões e síndrome músculo-esquelética em adolescentes obesos versus eutróficos e sua relação com o uso de computadores e vídeo-games. Dissertação (Mestrado) - Faculdade de Medicina, Universidade de São Paulo, São Paulo, 2011.

LWIN, May O.; MALIK, Shelly. Can exergames impart health messages? Game play, Framing and Drivers of Physical Activity Among Children. Journal of Health Communication, v. 19, n. 2, p. 136151, 2013.

MARCHETTI, Paulo Henrique et al. Jogos eletrônicos interativos "EXERGAMING": uma breve revisão sobre suas aplicações na Educação Física. Pulsar, v. 3, n. 1, p. 1-13, 2011. 
MOURA, Diego Luz; SOUSA, Cleyton Batista. A utilização de novas tecnologias em uma escola experimental do Rio de Janeiro. Educação Temática Digital - ETD, v. 16, n. 2, p. 346-361, 2014.

MUSSATO, Regiane; BRANDALIZE, Danielle; BRANDALIZE, Michelle. Nintendo Wiiß e seu efeito no equilíbrio e capacidade funcional de idosos saudáveis. Revista Brasileira de Ciência e Movimento, v. 20, n. 2, p. 68-75, 2012.

PEREZ, Carlos Rey; NEIVA, Jaqueline Freitas de Oliveira; MONTEIRO, Carlos Bandeira de Mello. A vivência da tarefa motora em ambiente virtual e real: estudo da devolução do saque do tênis de mesa. Pensar a Prática, v. 17, n. 1, p. 191-199, 2014.

QUINN, Margaret. Introduction of Active Video Gaming into the middle school curriculum as a schoolbased childhood obesity intervention. Journal of Health Care, v. 27, n. 1, p. 3-12, jan./fev. 2013.

RAUBER, Suliane Beatriz et al. Variáveis cardiovasculares durante e após a prática do vídeo game ativo "Dance Dance Revolution" e televisão. Motriz, v. 19, n. 2, p. 358-367, abr.jun. 2013.

SCHWARTZ, Gisele Maria et al. Apropriação das tecnologias virtuais como estratégias de intervenção no campo do lazer: os webgames adaptados. Licere, v. 16, n. 3, p. 1-26, 2013.

SGRÒ, Francesco et al. Exergames for physical education: an overview about interaction design perspectives. Word Journal on Education Technology, v. 5, n. 2, p. 248-256, 2013.

SHAYNE, Rachel K. et al. The effects of exergaming on physical activity in a third-grade physical education class. Journal of Applied Behavior Analysis, v. 45, n. 1, p. 211- 215, 2012.

SPOSITO, Letícia Aparecida Calderão et al. Experiência de treinamento com Nintendo Wiiß sobre a funcionalidade, equilíbrio e qualidade de vida de idosas. Motriz, v. 19, n. 2, p. 532-540, 2013.

SUN, Haichun. Exergaming impact on physical activity and interest in elementary school children. Quarterly for Exercise and Sport. v. 83, n. 2, p. 212-220, 2012.

VAGHETTI, César Augusto Otero; BOTELHO, Silvia Silva da Costa. Ambientes virtuais de aprendizagem na educação física: uma revisão sobre a utilização dos exergames. Ciência e Cognição, v. 15, n. 1, p. 76-88, 2010. 
